\title{
Integrated Coastal Management: lessons learned to address new challenges
}

\author{
Allan T. Williams ${ }^{1,2}$ \\ Published online: 4 September 2015 \\ (C) Springer Science+Business Media Dordrecht 2015
}

In 1969, the Stratton Commission presented to the US Congress a keystone report in the field of coastal management, which eventually culminated in the US Coastal Zone Management Act of 1973 that marked commencement of coastal management programmes in the USA. Since then the subject has gone global and now is being sub-summed into the area of Marine Spatial Planning. The Rio summit in 1992 provided a large impetus for Mediterranean regions and in 1995, the revised Barcelona Convention introduced the second phase of the Mediterranean Action Plan, to be followed 1 year later by the European Union funded Demonstration Programme on Integrated Coastal Zone Management. The end result of the above has been a plethora of global research activities from which many tools and instruments varying from simple to extremely sophisticated, have evolved together with approaches, such as, 'community/ecosystem based', 'satoumi,' etc.

A Global Congress on: 'Integrated Coastal Management (ICM):Lessons learned to address new challenges,' was held at Marmaris, Turkey, In November, 2013, organised by the Medcoast Coastal Foundation, Dalyan, Turkey and the International EMECS Centre, Kobe, Japan, co-organised with Sitki Koçman University, Muğla, Turkey. EU Projects PEGASO and MARLISCO contributed considerably to the outcome of the 186 papers presented and published. From these ten were selected for this Special Issue of the Journal of Coastal Conservation and Management and the topics were completely rewritten to a much greater depth. The main focus is the

Allan T. Williams

allan.williams@virgin.net

1 University of Wales Trinity St David, Swansea, UK

2 CICS NOVA, Nova Universidade de Lisboa, Lisboa, Portugal
Mediterranean and Black Seas, but three 'outliers' have been included, e.g. Kate Pike et al., investigated cultural ecosystem services in Canada and the UK using Q methodology to examine 'unmeasurable' values, converting qualitative, subjective data to quantitative information; whilst Peter Lawless gave three New Zealand case studies of sociometric and structural analyses utilised for local level consensus that could be transposed into regional and national administrative systems. A keynote presentation by Frank van der Meulen et al., concerned dune compensation issues in the Netherlands and its implications for dune areas elsewhere in the world.

Gonzalo C. Malvárez, Emilia G. Pintado, Fátima Navas \& Alessandro Giordano set the scene by looking at, 'Spatial data and its importance for the implementation of UNEP MAP ICZM Protocols for the Mediterranean.' One of the key elements of work carried out via the European Commission, Framework Programme 7, 2010, PEGASO project, was Spatial Data Infrastructure (SDI) development together with sustainability multiscale integrated assessments tools. The aim was to produce a model of Mediterranean and Black Sea regions that integrated data from different formats. Continuing with tools needed in ICM,

Mamuka Gvilava, Tamar Bakuradze \& Amiran Gigineishvili's, 'Easy to Use Tools for ICZM Progress Reporting and Coastal Indicators,' looked at how Black Sea countries utilised EU ICM indicators, and particularly stressed software issues. The Georgian coast was used as an example of the application of spectrum-type visualisation to coastal issues to derive coastal sustainability indicators and recommendation were made.

The environmental management modelling theme was carried on by the paper of Peter Lawless; 'Application of Sociometric Methods to Collaborative Coastal Management.' Three New Zealand case studies were analysed in a sociometric framework from pre-initiation research to completed 
legislation and consequent national implementation. The studies were the Kaikoura ICM programme; the South Marine Biosecurity Partnership, and the Hauraki Gulf Sea Change project. The conclusions were that collaborative processes were useful especially where overlapping interests affected multiple parties.

'The assessment of cultural ecosystem services in the marine environment using Q methodology, 'by Kate Pike, Paul Wright, Brian Wink, \& Steve Fletcher, investigated cultural ecosystem services, which are normally taken to have nonmaterial value, e.g. a sense of well being. This frequently makes subjective judgements hard to quantify. Q methodology examined stakeholder views of cultural values and two case studies are presented. The findings were that three predominant 'factors' of value existed for stake holders.

A detailed study, 'Multiple DPSI frameworks for support of integrated research: a case study of the Bahía de Cádiz Nature Park (Spain), by Sarah Camilleri, Alejandro PérezHurtado de Mendoza, \& Giovanni Gabbianelli, epitomised the system thinking approach to support a review of political and management instruments and elements that characterized the investigated Park. The Driver-Pressure-State-ImpactResponse (DPSIR) framework identified social and environmental dimensional elements, but failed to cover temporal and spatial dimensions when certain elements were present.

Public perception and social network analysis for coastal risk management in Maresme Sud (Barcelona, Catalonia), by Elisabet Roca, Míriam Villares, \& Oroval Laia, \& Adrián Gabarró, investigated how improvements could be made in current governance systems to achieve a better adaptive coastal landscape risk management methodology. Structured interviews from a spectrum of stakeholders indicated that public body presence made integration difficult and the role of supralocal stakeholders should be enhanced.

Two dune studies are given, the first by Frank Van Der Meulen. Bert van der Valk, Kees Vertegaal, Mennobart van
Eerden \& Bas Arens, dealt with, 'Building with nature at the Dutch dune coast: compensation target management in Spanjaards Duin at EU and regional policy levels.' This looked at the political and management aspects of a new dune area located in the SW delta area of the Netherlands, built as compensation due to Maasvlakte 2 (MV-2), the new extension of Rotterdam harbour. Results from the highly innovative nature of this project can be utilised globally. The second was by Oxana Sytnik and dealt with, 'Disappearing coastal dunes: tourism development and future challenges, a case-study from Ravenna, Italy.' The paper traced the historical growth of tourism and its effect on the Ravenna dunes. ArcGIS analysis was used and findings indicated that large areas of dune (18 ha in circa 60 years) have been removed due to beach establishment construction in this highly popular tourist area.

Fatma Aycim Turer Baskaya, leaves the countryside for the city and looked at, 'Disaster Sensitive Landscape Planning and Coastal Megacity of Istanbul, Turkey.' Two Istanbul hazard zones were taken as case studies and via GIS, their open space responses were evaluated, a process that involved six phases: examining the landscape and its changes, detecting current urban elements, eliminating unavailable urban elements for emergency response, defining open space and cluster types for the postearthquake period, assigning clusters and open spaces, and defining strategies.

Allan Williams and Abtellatif Khattabi, investigated 21 beach sites for, 'Beach scenery at Nador province, Morocco.' They used a semi-quantitative weighted 26 parameter checklist to assess coastal scenery, to which fuzzy logic was applied. A five point scenery division scale was presented, which ranged from excellent scenery to poor scenery. In order to attract tourists, coastal managers can do little with respect to landscape physical parameters and should concentrate on the human ones. 